

\title{
Promotive effect of comprehensive management on achieving blood glucose control in senile type 2 diabetics
}

\author{
S.-T. Yan, C.-X. Li, C.-L. Li, J. Li, Y.-H. Shao, Y. Liu, W.-W. Zhong, \\ F.-S. Fang, B.-R. Sun and H. Tian \\ Department of Geriatric Endocrinology, PLA General Hospital, Beijing, China \\ Corresponding author: H. Tian \\ E-mail: stthcn@126.com
}

Genet. Mol. Res. 14 (2): 3062-3070 (2015)

Received May 11, 2014

Accepted November 4, 2014

Published April 10, 2015

DOI http://dx.doi.org/10.4238/2015.April.10.16

ABSTRACT. The aim of this study was to evaluate the control of
blood glucose and glycosylated hemoglobin A1c (HbAlc) and its
influencing factors, in elderly type 2 diabetic mellitus (T2DM) patients
undergoing comprehensive management. After years of comprehensive
prevention of and control measures for diabetes, elderly T2DM patients
who were receiving long-term health care were comprehensively
evaluated through an annual physical examination. In addition to
routine health examination, the patients were required to undergo
HbA1c measurement. Among 688 patients, 652 were men and 36 were
women, with a mean age of $78.2 \pm 9.1$ years. The average HbA1c was
$6.6 \pm 0.9 \%$. A total of $50.6 \%$ of the patients had HbA1c $<6.5 \%$, whereas
$76.3 \%$ had HbA1c $<7.0 \%$. Among all patients, $77.1,46.4,66.1,67.8$,
36.3 , and $57.4 \%$ achieved the target total cholesterol, low-density
lipoprotein (LDL), high-density lipoprotein (HDL), triglyceride (TG),
blood pressure, and body mass index (BMI) levels, respectively. The
duration of disease and type of treatment, as well as the LDL, HDL,
TG, BMI, and blood pressure levels, were significantly associated with 
HbA1c control. No patient was admitted because of ketoacidosis or hyperosmolar nonketotic diabetic coma in 10 years. Approximately half of the T2DM patients achieved the target HbA1c level. The more effective blood glucose control observed in our study compared with previous studies can be attributed to the effective monitoring of medical conditions and comprehensive management of patients.

Key words: Type 2 diabetes mellitus; Glycosylated hemoglobin; Influencing factors

\section{INTRODUCTION}

Diabetes mellitus (DM) has become a globally important public health problem. Experts have predicted that the number of diabetics worldwide will reach 0.366 billion by 2030 . Among this population, Chinese patients will comprise $>42.30$ million. However, the Chinese Diabetes Society (CDS), through its 2008 national census, found the number of diabetics in China to be approximately 94.50 million. This value was 1.23 times the estimated number (Yang et al., 2010). The severe acute or chronic complications of diabetes are the major factors that result in death and disability. Thus, long-term satisfactory blood glucose control is important in the management and delay of acute and chronic complications.

Previous studies indicated that the risks for heart disease and cerebral apoplexy in DM patients increase by $1 \%$ when glycosylated hemoglobin A1c (HbAlc) increases by $18 \%$ (Nathan et al., 2006). Given that strict blood glucose control may reduce the possibility of capillary complications in type 2 DM (T2DM), the International Diabetes Federation (IDF) and American Diabetes Association (ADA) recommended an $\mathrm{HbA} 1 \mathrm{c}$ level of $<7 \%$ as the goal for blood glucose control (Selvin et al., 2004; Nathan et al., 2009; International Diabetes Federation, 2014). A recent cross-sectional study by the CDS showed that blood glucose control in Chinese DM patients is unsatisfactory (Pan et al., 2009), on the basis of the DiabCare investigation conducted in 60 large-scale medical centers for diabetes and in city central hospitals in 2006. The average HbA1c level for T2DM was found to be 7.6\%. Among all patients, $77 \%$ did not exhibit a qualified HbA1c level $(\geq 6.5 \%)$ (Harris et al., 2005). The prevalence of DM is known to be related to age. The elderly are more susceptible to DM. Moreover, the elderly population is rapidly growing globally and in China. The most recent Centers for Disease Control (CDC) and Prevention Diabetes Fact Sheet noted the high prevalence of diabetes in the elderly, with approximately $30 \%$ being affected (Prevention CDC, 2011). The improvement of diabetes management for this growing population is important, both in terms of improved health outcomes and economics (American Diabetes Association, 1998). The basic goal of diabetes management in older adults is similar to that for the younger population. For instance, the prevention of microvascular and macrovascular diseases is a similar goal. However, as patients with diabetes age, they experience challenges such as memory problems, vision/hearing impairment, depression, and difficulty in performing daily routines. These disorders are called "geriatric syndromes" (Munshi, 2008; Araki and Ito, 2009). Geriatric syndromes such as cognitive dysfunction, depression, and functional disability have subtle presentations and, thus, can only be identified if providers specifically look for them (Brown et al., 2003; Munshi et al., 2006). Moreover, additional medical comorbidities pose difficulties for the elderly in terms of maintaining self-management activities necessary for diabetes treatment (Sinclair et al., 2000; 
Brown et al., 2003). The additional burden of polypharmacy, which is a common problem in this population, may also increase the risk of drug interactions and adverse effects (Kaufman et al., 2002; Sergi et al., 2011). All the given factors make glycemic control difficult.

In this study, we conducted a cross-sectional investigation on the glycemic control level in middle-aged and senile diabetics with satisfactory health-care conditions after a multilevel integrative diabetic management, with the aim of examining the qualification rates of $\mathrm{HbAlc}$ and other metabolic control indices as well as potential influential factors.

\section{MATERIAL AND METHODS}

\section{Subjects}

Middle-aged and senile patients accepted long-term, regular physical examinations and treatment in our hospital. Screening for diabetes was conducted during the yearly physical examination starting from 1996 (patients who showed a blood glucose level $>7.2 \mathrm{mM}$ at $2 \mathrm{~h}$ after a meal of steamed bread were subjected to an oral glucose tolerance test for the final diagnosis). From 1998, multilevel integrative diabetes management including 1) education on the prevention and treatment for confirmed diabetics and their families (classes and manuals); 2) prompt monitoring of blood glucose level for diabetics and timely management for diabetics with high blood glucose level in the physical examinations, including group studies in clinic classes and short-term hospitalization for adjustment and treatments; 3) lectures on diabetes and integrative control measurements for other related metabolic abnormalities in primary-level health-care units; and 4) regular classes on advancements in the prevention and treatment of diabetes and metabolic syndrome for health-care staff in primary-level units. This study was conducted in accordance with the Declaration of Helsinki and with approval from the Ethics Committee of PLA General Hospital. Written informed consent was obtained from all participants.

All confirmed type 2 diabetics were subjected to $\mathrm{HbA1c}$ measurements besides the usual physical examination items during the annual physical examinations in May 2009. All type 2 diabetics met the diagnostic criteria for diabetes by the World Health Organization in 1999, and their disease courses were longer than half a year. These patients did not have any acute complication of diabetes or serious infectious diseases. Patients with hepatic inadequacy, renal inadequacy, and anemia were excluded during the HbAlc calculation.

\section{Evaluation}

All subjects were evaluated for height, body weight, and blood pressure by designated staff members. Body mass index (BMI) was also calculated. Venous blood samples were collected from patients who had fasted for $>8 \mathrm{~h}$, to detect blood lipids and HbAlc. Blood lipids were measured on a 7600 automated biochemical analyzer from Hitachi Company (Tokyo, Japan). HbA1c was measured by using high-performance liquid chromatography on a Variant II automated glycosylated hemoglobin analyzer from Bio-Rad Corporation (USA). The reference range for the measured value was 4.1 to $6.5 \%$.

The criteria for $\mathrm{HbA} 1 \mathrm{c}$ control were calculated according to the recommendation of the IDF and ADA. The criteria for blood pressure and blood lipid control for type 2 diabetics were implemented according to the 2008 ADA guidelines. The requirements for qualification 
were blood pressure $<130 / 80 \mathrm{mmHg}$, total cholesterol (TC) $<5.2 \mathrm{mM}$, low-density lipoprotein (LDL) $<2.6 \mathrm{mM}$, high-density lipoprotein (HDL) $\geq 1.0 \mathrm{mM}$ for men and $\geq 1.3 \mathrm{mM}$ for women, triglyceride $(\mathrm{TG})<1.7 \mathrm{mM}$, and $\mathrm{BMI}<25 \mathrm{~kg} / \mathrm{m}^{2}$.

\section{Statistical analysis}

SPSS 11.5 (SPSS Inc., Chicago, IL, USA) was used to establish the database. The measurement data are reported as means $\pm \mathrm{SD}$, and the enumeration data were subjected to a chi-square test. $\mathrm{P}<0.05$ indicated a statistically significant difference.

\section{RESULTS}

\section{Basic information}

A total of 708 middle-aged and senile type 2 diabetics were included in the 2009 evaluations. This number accounted for $35.9 \%$ of the patients who underwent the annual physical examination. A total of 20 patients with renal inadequacy or anemia were excluded. Thus, 688 patients were included in this study, 672 of whom were men and 36 were women. The average age for all patients was $78.2 \pm 9.1$ years. According to the criteria for control recommended by the CDS, the BMI, blood pressure, and blood lipid (LDL was excluded) averages of the subjects were controlled within the ranges for qualification. The LDL average was $2.7 \pm 0.8 \mathrm{mM}$, which was slightly higher than the criteria for control (Table 1).

In terms of the treatments for blood glucose reduction, $95 \%$ of the patients followed a normal lifestyle, $23.4 \%$ of the diabetics controlled their blood glucose level simply with diet and exercise, $20.5 \%$ took an oral antidiabetic drug, and 30.1\% took several oral antidiabetic drugs. Patients who took insulin and those who took insulin in combination with oral antidiabetic drugs accounted for 4.1 and $13.1 \%$ of the population, respectively. Moreover, $59.3 \%$ of the patients had no history of smoking, $28.1 \%$ had a history of smoking but had already quit, and $12.5 \%$ remained as smokers.

Table 1. Basic clinical data of type 2 diabetes mellitus patients.

\begin{tabular}{lcc}
\hline & Mean \pm SD & Minimum-maximum \\
\hline Age (years) & $76.8 \pm 9.9$ & $60-95$ \\
BMI (kg/m ${ }^{2}$ ) & $24.7 \pm 3.0$ & $14-35$ \\
DM duration (years) & $11.0 \pm 8.3$ & $0.5-55$ \\
TC $(\mathrm{mM})$ & $4.6 \pm 0.9$ & $2.2-7.7$ \\
TG $(\mathrm{mM})$ & $1.6 \pm 1.1$ & $0.3-12$ \\
LDL (mM) & $2.7 \pm 0.8$ & $0.5-5.3$ \\
HDL (mM) & $1.2 \pm 0.3$ & $0.5-2.6$ \\
Systolic blood pressure (mmHg) & $130.1 \pm 12.1$ & $95-170$ \\
Diastolic blood pressure (mmHg) & $71.8 \pm 8.7$ & $45-100$ \\
\hline
\end{tabular}

$\mathrm{SD}=$ standard deviation; $\mathrm{BMI}=$ body mass index $; \mathrm{DM}=$ diabetes mellitus; $\mathrm{TC}=$ total cholesterol; $\mathrm{TG}=$ triglyceride; $\mathrm{LDL}=$ low-density lipoprotein; HDL = high-density lipoprotein .

\section{Qualification for blood glucose, blood pressure, blood lipids, and BMI control}

As shown in Table 2, according to the recommended criteria by the CDS, 348 diabetics (50.6\%) showed HbA1c levels $<6.5 \%, 177$ (25.7\%) showed HbA1c levels between 6.5 and 
$7 \%, 119(17.3 \%)$ had their HbA1c level controlled between 7.0 and $8.0 \%$, and only $44(6.5 \%)$ showed poorly controlled blood sugar with an HbA1c level of not lower than $8.0 \%$. According to the ADA criteria, $\mathrm{HbA} 1 \mathrm{c}<7.0 \%$ can be considered as the qualification requirement for control. As a result, 525 patients $(76.3 \%)$ met the requirement.

Table 2. Horizontal distribution of $\mathrm{HbA} 1 \mathrm{c}$ in elderly type 2 diabetes mellitus patients.

\begin{tabular}{lcc}
\hline HbA1c & Mean \pm SD & $\mathrm{N}(\%)$ \\
\hline$<5.5$ & $5.2 \pm 0.3$ & $22(3.2)$ \\
$5.5-6.5$ & $6.0 \pm 0.2$ & $326(47.4)$ \\
$6.5-7.0$ & $6.7 \pm 0.1$ & $177(25.7)$ \\
$7.0-8.0$ & $7.3 \pm 0.3$ & $119(17.3)$ \\
$8.0-10.0$ & $8.7 \pm 0.4$ & $37(5.4)$ \\
$\geq 10$ & $10.8 \pm 0.5$ & $7(1.0)$ \\
Total & $6.6 \pm 0.9$ & $688(100)$ \\
\hline
\end{tabular}

$\mathrm{HbA1c}=$ glycosylated hemoglobin A1c.

As shown in Table 3, among the 688 type 2 diabetics, the qualification rates for TC, TG, LDL, HDL, blood pressure, and BMI were 77.1, 67.8, 46.4, 66.1, 36.3, and 57.4\%, respectively, in accordance with the 2008 ADA guidelines. Systolic blood pressure control was poor, whereas diastolic blood pressure control easily met the requirement, which was consistent with the characteristics of senile diabetics.

Table 3. Status of control of blood fat, blood pressure, and BMI in elderly T2DM patients.

\begin{tabular}{lcc}
\hline & Mean \pm SD & Standard rate $(\%)$ \\
\hline TC $(\mathrm{mM})$ & $4.5 \pm 0.9$ & 77.1 \\
TG $(\mathrm{mM})$ & $1.6 \pm 1.1$ & 67.8 \\
LDL $(\mathrm{mM})$ & $2.7 \pm 0.8$ & 46.4 \\
HDL (mM) & $1.2 \pm 0.3$ & 66.1 \\
BMI (kg/m $)$ & $24.6 \pm 3.1$ & 57.4 \\
Blood pressure $(\mathrm{mmHg})$ & $130.0 \pm 12.5$ & 36.3 \\
Systolic & $71.2 \pm 7.0$ & 42.8 \\
Diastolic & 71.3 \\
\hline
\end{tabular}

$\mathrm{BMI}=$ body mass index; $\mathrm{T} 2 \mathrm{DM}=$ type 2 diabetes mellitus; $\mathrm{TC}=$ total cholesterol; $\mathrm{TG}=$ triglyceride LDL $=$ lowdensity lipoprotein; HDL = high-density lipoprotein.

\section{Influencing factors for $\mathrm{HbA1c}$ control}

As shown in Table 4, when the duration of diabetes was $>10$ years or when TG, LDL, $\mathrm{HDL}$, blood pressure, and BMI were not controlled to meet the requirements, HbA1c control was always unsatisfactory. The HbAlc control in patients who accepted insulin in combination with oral antidiabetic drugs was poorer than in those who simply followed a diet and exercise regimen, as well as in those who were orally administered with a single drug. On the other hand, age, gender, and smoking were not significantly correlated with HbA1c control.

\section{Safety evaluations}

Statistical analysis was conducted during 10 years for the health care of the subjects. No patient was hospitalized because of emergent treatments for diabetic ketoacidosis or hyperosmolar hyperglycemic status. Three patients received emergency treatment for serious or 
moderate hypoglycemia. Among these patients, two took additional traditional Chinese medicines by themselves (one patient took a medicine that contains glibenclamide, whereas the other patient took a medicine with unknown ingredients). The third patient did not consume food after insulin injection. No death occurred as a result of diabetes.

\section{Table 4. Influencing factors of $\mathrm{HbAlc}$ control.}

\begin{tabular}{|c|c|c|c|c|c|}
\hline & \multirow{2}{*}{$\begin{array}{c}\mathrm{HbAlc} \\
(\text { mean } \pm \mathrm{SD})\end{array}$} & \multicolumn{3}{|c|}{ HbAlc [N (\%)] } & \multirow[t]{2}{*}{ P value } \\
\hline & & $<6.5$ & $6.5-7.0$ & $\geq 7.0$ & \\
\hline \multicolumn{5}{|l|}{ Age (years) } & \multirow{4}{*}{0.172} \\
\hline $60-70$ & $6.5 \pm 0.8$ & $86(52.1)$ & $44(26.7)$ & $35(21.2)$ & \\
\hline $70-80$ & $6.5 \pm 0.8$ & $98(55.4)$ & $44(24.9)$ & $35(19.8)$ & \\
\hline$\geq 80$ & $6.7 \pm 0.9$ & $164(47.4)$ & $89(25.7)$ & $93(26.9)$ & \\
\hline \multicolumn{5}{|l|}{ Gender } & \multirow[t]{3}{*}{0.754} \\
\hline Male & $6.6 \pm 0.9$ & $333(51.1)$ & $162(24.8)$ & $157(24.1)$ & \\
\hline Female & $6.6 \pm 0.8$ & 15 (41.6) & $15(41.6)$ & $6(16.8)$ & \\
\hline \multicolumn{5}{|l|}{ Disease duration (years) } & \multirow[t]{3}{*}{0.000} \\
\hline$<10$ & $6.4 \pm 0.7$ & $185(62.3)$ & $68(22.9)$ & $44(14.8)$ & \\
\hline$\geq 10$ & $6.8 \pm 1.0$ & $156(41.3)$ & $105(27.8)$ & $117(30.9)$ & \\
\hline \multicolumn{5}{|l|}{$\mathrm{BMI}\left(\mathrm{kg} / \mathrm{m}^{2}\right)$} & \multirow[t]{3}{*}{0.000} \\
\hline$<25$ & $6.6 \pm 0.9$ & $170(50.1)$ & $81(23.9)$ & $88(26.0)$ & \\
\hline$\geq 25$ & $6.7 \pm 1.0$ & $112(44.8)$ & $77(30.8)$ & $61(24.4)$ & \\
\hline \multicolumn{5}{|l|}{ Smoking or not } & \multirow{4}{*}{0.449} \\
\hline Smoking & $6.6 \pm 0.9$ & $36(48.0)$ & $19(25.3)$ & $20(26.7)$ & \\
\hline Gave up smoking & $6.7 \pm 0.8$ & $68(41.2)$ & $51(30.9)$ & $46(27.9)$ & \\
\hline Nonsmoking & $6.6 \pm 1.0$ & $184(51.8)$ & $88(24.8)$ & $83(23.4)$ & \\
\hline \multicolumn{5}{|l|}{ Drug } & \multirow[t]{5}{*}{0.000} \\
\hline Diet control only & $6.2 \pm 0.5$ & $119(74.8)$ & $29(18.2)$ & $11(6.9)$ & \\
\hline Single oral agents & $6.4 \pm 0.6$ & $82(57.7)$ & $40(28.2)$ & $20(14.1)$ & \\
\hline Combined oral agents & $6.7 \pm 0.9$ & $87(41.2)$ & $71(33.6)$ & $53(25.1)$ & \\
\hline Insulin* & $7.2 \pm 1.1$ & $24(21.1)$ & $26(22.8)$ & $64(56.1)$ & \\
\hline \multicolumn{5}{|l|}{$\mathrm{TC}(\mathrm{mM})$} & \multirow[t]{3}{*}{0.435} \\
\hline$<5.2$ & $6.6 \pm 0.9$ & $258(49.1)$ & $136(25.9)$ & $131(25.0)$ & \\
\hline$\geq 5.2$ & $6.5 \pm 0.9$ & $86(54.8)$ & $41(26.1)$ & $30(19.1)$ & \\
\hline \multicolumn{5}{|l|}{$\mathrm{TG}(\mathrm{mM})$} & \multirow[t]{3}{*}{0.001} \\
\hline$<1.7$ & $6.5 \pm 0.8$ & $250(53.4)$ & $117(25.0)$ & $101(21.6)$ & \\
\hline$\geq 1.7$ & $6.7 \pm 1.0$ & $94(44.1)$ & $59(27.7)$ & $60(28.2)$ & \\
\hline \multicolumn{5}{|l|}{ LDL (mM) } & \multirow[t]{3}{*}{0.000} \\
\hline$<2.6$ & $6.6 \pm 0.8$ & $152(48.4)$ & $79(25.2)$ & $83(26.4)$ & \\
\hline$\geq 2.6$ & $6.6 \pm 0.9$ & $192(52.2)$ & $98(26.6)$ & $78(21.2)$ & \\
\hline \multicolumn{5}{|l|}{$\mathrm{HDL}(\mathrm{mM})$} & \multirow[t]{3}{*}{0.000} \\
\hline Male $<1.0$ female $<1.3$ & $6.8 \pm 1.0$ & $84(37.5)$ & $63(28.1)$ & $77(34.3)$ & \\
\hline & $6.5 \pm 0.8$ & $260(56.8)$ & 114 (24.9) & 84 (18.3) & \\
\hline \multicolumn{5}{|l|}{ Blood pressure $(\mathrm{mmHg})$} & \multirow{3}{*}{0.020} \\
\hline$<130 / 80$ & $6.6 \pm 0.9$ & $111(50.7)$ & $55(25.1)$ & $53(24.2)$ & \\
\hline$\geq 130 / 80$ & $6.8 \pm 1.0$ & $178(46.7)$ & $104(27.3)$ & $99(26.0)$ & \\
\hline
\end{tabular}

BMI, body mass index; HbA1c, glycosylated hemoglobin A1c; TC, total cholesterol; TG, triglyceride; LDL, lowdensity lipoprotein; HDL, high-density lipoprotein *Including those who used insulin alone and those who used insulin combined with oral antidiabetic drugs.

\section{DISCUSSION}

Satisfactory blood glucose control is not only the short-term therapeutic goal for T2DM but is also the basis for realizing long-term therapeutic goals in reducing or postponing complications, improving survival quality, and reducing social and economic burdens. $\mathrm{HbA} 1 \mathrm{c}$ is generally used as an index for the evaluation of blood glucose control. Two different sets of criteria are currently available. The CDS recommend the control of blood glucose at 
$<6.5 \%$, whereas the IDF and ADA recommend the control of blood glucose at $<7.0 \%$. A 2005 study in Canada showed that the HbA1c level was $<7.0$ in $51 \%$ of T2DM patients and that the mean HbA1c level was 7.3\% (Harris et al., 2005). The results from a 2006 US study [National Health and Nutrition Examination Survey (NHANES) III] showed that 40.5 and $42.3 \%$ of the patients exhibited HbA1c levels <7.0\% (Harris, 2000; Spann et al., 2006). A 2009 study in Jordan showed that the mean $\mathrm{HbA} 1 \mathrm{c}$ level in T2DM patients was $7.1 \%$, and that $51.6 \%$ of the patients showed an HbA1c level $<7.0 \%$ (Al Omari et al., 2009). An investigation on diabetic control and management was conducted in 30 grade 3 class A hospitals in China in 2003. The results revealed that the mean $\mathrm{HbAlc}$ level was $7.5 \pm 1.6 \%$ among the subjects, which decreased by $1.4 \%$ compared with that in 1998 . However, only $11.5 \%$ of the patients met the requirements $(\mathrm{HbA} 1 \mathrm{c}<6.5 \%)$. The second DiabCare investigation in China, conducted in 2006, showed that the mean $\mathrm{HbA} 1 \mathrm{c}$ level in T2DM patients was 7.6\%. Moreover, the HbA1c level in $77 \%$ of the patients was not lower than $6.5 \%$, and that in $40 \%$ of the patients was $<7.0 \%$ (Pan et al., 2009). Compared with the rapidly increasing number of diabetics, the general control level among diabetics in China is not optimistic.

The senile T2DM patients in this study had relatively satisfactory integrative management and health-care levels of diabetes. The mean $\mathrm{HbAlc}$ level in the annual examination was $6.6 \%$, in accordance with the criteria recommended by the IDF, where $50.6 \%$ of the patients met the requirements. According to the criteria recommended by the ADA, $76.1 \%$ of the patients met the requirements. For the senile patient group aged 80 years and older, $47.4 \%$ of the patients showed an $\mathrm{HbAlc}$ level $<6.5$, and $73.1 \%$ showed an $\mathrm{HbA} 1 \mathrm{c}$ level $<7.0 \%$. In terms of the correlation between age and the HbA1c qualification rate, no significant correlation was found between these factors, which were consistent with the results from the study in Jordan (Khattab et al., 2010). This result implies that satisfactory diabetic management in senile diabetics is the most important decisive factor influencing blood glucose control, whereas age is not a barrier.

According to the guidelines presented by the ADA in 2008, the qualification rates for TC, LDL, HDL, TG, blood pressure, and BMI were 77.1, 46.4, 66.1, 67.8, 36.3, and 57.4\%, respectively. Except for blood pressure and LDL, the qualification rates for the other items were all $>50 \%$. The qualification rate for blood pressure was similar to that found in a US investigation, where blood pressure was $<130 / 85 \mathrm{mmHg}$ in $35.3 \%$ of the patients (Spann et al., 2006). Although the qualification rate for LDL in this present study is relatively low, the value is significantly higher than that in the investigation by NHANES III, where the LDL level was $<2.6 \mathrm{mM}$ in $15.4 \%$ of the patients.

The factors influencing the HbAlc level were analyzed. The data showed that the difficulties in sugar-reducing treatments were significant and that $\mathrm{HbAlc}$ control was poorer when the disease course of diabetes was long, which is consistent with the results from previous studies (Harris et al., 2005; Khattab et al., 2010). These results may be attributed to the functional failure of pancreatic island $\beta$ cells, low capability for controlling blood glucose, and increase in the difficulties of the control. Compared with patients who were orally administered with several sugar-reducing drugs and those who were using insulin, the control of $\mathrm{HbA} 1 \mathrm{c}$ level was satisfactory depending on diet and exercise. Patients who were orally administered with a sugar-reducing drug showed similar results as those in previous studies (Goudswaard et al., 2004; Khattab et al., 2010). Furthermore, the results from the present study showed that the control of TG, LDL, HDL, BMI, and blood pressure was correlated with blood glucose level, which further highlights the importance of the integrative control of multiple metabolic abnormalities in diabetics. Treatments for blood lipid regulation and blood 
pressure reduction, as well as control of body weight, cannot be neglected despite the active treatments for blood sugar reduction.

An investigation on the correlation between smoking, glycosylated hemoglobin, and proteinuria in Sweden showed that the mean HbA1c level in smoking diabetics was higher than that in nonsmoking patients and that the percentage of patients showing an $\mathrm{HbA} 1 \mathrm{c}$ level $<6.5 \%$ was lower than that in the nonsmoking group (Nilsson et al., 2004). Although we cannot conclude that smoking is correlated with the control of $\mathrm{HbA} 1 \mathrm{c}$ based on the data from the present study, a significance level of $\mathrm{P}<0.05$ in the comparison between the simple smoking group and the nonsmoking group indicates that smoking may affect the control of glycosylated hemoglobin to some extent.

Blood glucose control was generally correlated with the course of diabetes, drug medication, LDL, HDL, TG, BMI, and blood pressure. Integrative management for T2DM patients should thus be emphasized. The subjects for investigation in this present study were senile patients $>60$ years old. Although the patients' average age was high, their educational degree was also high. Thus, the diabetes screening process was well understood, and educational instructions on diabetes can be regularly conducted. Moreover, the self-management and compliance with treatments, as well as the health-care conditions of the patients, were satisfactory, and the patients were able to achieve satisfactory integrative management and control of blood pressure, blood lipids, and blood sugar. These advantages are all potential reasons for the high qualification rate of $\mathrm{HbAlc}$ in the present study compared with that in other Chinese reports.

\section{REFERENCES}

Al Omari M, Khader Y, Dauod AS, Al-Akour N, et al. (2009). Glycaemic control among patients with type 2 diabetes mellitus treated in primary care setting in Jordan. Prim. Care Diabetes 3: 173-179.

American Diabetes Association (1998). Economic consequences of diabetes mellitus in the U.S. in 1997. Diabetes Care 21: 296-309.

Araki A and Ito H (2009). Diabetes mellitus and geriatric syndromes. Geriatr. Gerontol. Int. 9: 105-114.

Brown AF, Mangione CM, Saliba D, Sarkisian CA, et al. (2003). Guidelines for improving the care of the older person with diabetes mellitus. J. Am. Geriatr. Soc. 51: S265-S280.

Goudswaard AN, Stolk RP, Zuithoff P and Rutten GE (2004). Patient characteristics do not predict poor glycaemic control in type 2 diabetes patients treated in primary care. Eur. J. Epidemiol. 19: 541-545.

Harris MI (2000). Health care and health status and outcomes for patients with type 2 diabetes. Diabetes Care 23: 754-758.

Harris SB, Ekoé JM, Zdanowicz Y and Webster-Bogaert S (2005). Glycaemic control and morbidity in the Canadian primary care setting (results of the diabetes in Canada evaluation study). Diabetes Res. Clin. Pract. 70: 90-97.

International Diabetes Federation (2014). Global guideline for type 2 diabetes. Diabetes Res. Clin. Pract. 104: 1-52.

Kaufman DW, Kelly JP, Rosenberg L, Anderson TE, et al. (2002). Recent patterns of medication use in the ambulatory adult population of the United States: the Slone survey. JAMA 287: 337-344.

Khattab M, Khader YS, Al-Khawaldeh A and Ajlouni K (2010). Factors associated with poor glycaemic control among patients with type 2 diabetes. J. Diabetes Compl. 24: 84-89.

Munshi M (2008). Managing the "geriatric syndrome" in patients with type 2 diabetes. Consult. Pharm. 23: 12-16.

Munshi M, Grande L, Hayes M, Ayres D, et al. (2006). Cognitive dysfunction is associated with poor diabetes control in older adults. Diabetes Care 29: 1794-1799.

Nathan DM, Buse JB, Davidson MB, Heine RJ, et al. (2006). Management of hyperglycemia in type 2 diabetes: a consensus algorithm for the initiation and adjustment of therapy: a consensus statement from the American Diabetes Association and the European Association for the Study of Diabetes. Diabetes Care 29: 1963-1972.

Nathan DM, Buse JB, Davidson MB, Ferrannini E, et al. (2009). Medical management of hyperglycemia in type 2 diabetes: a consensus algorithm for the initiation and adjustment of therapy: a consensus statement of the American Diabetes Association and the European Association for the Study of Diabetes. Diabetes Care 32: 193-203.

Nilsson PM, Gudbjörnsdottir S, Eliasson B, Cederholm J, et al. (2004). Smoking is associated with increased HbA1c values and microalbuminuria in patients with diabetes - data from the national diabetes register in Sweden. Diabetes 
Metab. 30: 261-268.

Pan C, Yang W, Jia W, Weng J, et al. (2009). Management of Chinese patients with type 2 diabetes, 1998-2006: the DiabCare-China surveys. Curr. Med. Res. Opin. 25: 39-45.

Prevention CDC (2011). National diabetes fact sheet: national estimates and general information on diabetes and prediabetes in the United States. US Department of Health and Human Services, Centers for Disease Control and Prevention, Atlanta.

Selvin E, Marinopoulos S, Berkenblit G, Rami T, et al. (2004). Meta analysis: glycosylated hemoglobin and cardiovascular disease in diabetes mellitus. Ann. Intern. Med. 141: 421-131.

Sergi G, De Rui M, Sarti S and Manzato E (2011). Polypharmacy in the elderly: can comprehensive geriatric assessment reduce inappropriate medication use? Drugs Aging 28: 509-518.

Sinclair AJ, Girling AJ and Bayer AJ (2000). Cognitive dysfunction in older subjects with diabetes mellitus: impact on diabetes self-management and use of care services. All Wales Research into Elderly (AWARE) Study. Diabetes Res. Clin. Pract. 50: 203-212.

Spann SJ, Nutting PA, Galliher JM, Peterson KA, et al. (2006). Management of type 2 diabetes in the primary care setting: a practice-based research network study. Ann. Fam. Med. 4: 23-31.

Yang W, Lu J, Weng J, Jia W, et al. (2010). Prevalence of diabetes among men and women in China. N. Engl. J. Med. 362: 1090-1101. 